\title{
LONG-TERM DISTRIBUTIONAL DYNAMICS OF A MICHIGAN AMPHIBIAN ASSEMBLAGE
}

\author{
David K. Skelly, ${ }^{1}$ Earl E. Werner, ${ }^{2}$ and Spencer A. Cortwright ${ }^{3}$ \\ ${ }^{1}$ School of Forestry and Environmental Studies, and Department of Ecology and Evolutionary Biology, \\ Yale University, 370 Prospect Street, New Haven, Connecticut 06511 USA \\ ${ }^{2}$ Department of Biology, University of Michigan, Ann Arbor, Michigan 48109 USA \\ ${ }^{3}$ Department of Biology, Indiana University Northwest, Gary, Indiana 46408 USA
}

\begin{abstract}
From 1988 to 1992 we surveyed the distribution of 14 amphibian species in a set of 37 ponds in southeastern Michigan, USA. Thirty-two of these ponds had been surveyed previously between 1967 and 1974 . We found that the distributions of amphibian populations (1988-1992) were strongly related to two habitat characteristics: pond hydroperiod and forest canopy cover. Most species exhibited nonrandom distributions with respect to these pond characteristics. Between surveys, the distribution of each species changed, and most species experienced multiple population colonizations and extinctions. Turnover in the distribution of populations among ponds (estimated via Jaccard's similarity coefficient) averaged nearly $50 \%$ among species. The substantial number of species colonizations (40 cases) and extinctions (34 cases) between surveys resulted in little net change in number of breeding populations for most species; just four species experienced net changes of more than two populations. Historical information indicated that, for many ponds, hydroperiod and canopy cover changed between surveys. In several cases habitat changes associated with forest succession apparently had negative impacts on amphibian populations. In ponds that now dry each summer and are under closed canopies, two-thirds of the breeding populations present during 1967-1974 were extinct during the recent survey. No population colonizations occurred in these ponds between surveys, in marked contrast to other ponds, in most of which amphibian species richness either was maintained or increased. In addition, tendencies for ponds to experience population colonizations and extinctions also were associated with pond isolation. Our results highlight the volatile nature of amphibian distributions and point to forest succession, via its effects on canopy and hydroperiod, as a potential force shaping the dynamics of amphibian populations.
\end{abstract}

Key words: amphibians; canopy cover, effects on amphibians; distribution, amphibians; forest canopy cover and amphibians; Michigan, USA; pond hydroperiod; succession.

\section{INTRODUCTION}

The study of processes responsible for ecological patterns has often focused on small areas considered for relatively short periods of time. A number of authors have pointed to the potential pitfalls of this approach (Kareiva and Anderson 1988, Levin 1992, Brown 1995). In particular, small scale studies offer a limited view of both the dynamics in population and community patterns and the mechanisms responsible. However, with relatively few exceptions (e.g., study of the role of succession in many plant and fewer animal communities), ecologists are just beginning to comprehensively address larger scale patterns and mechanisms (Levin 1992). Consequently, further studies are needed to document larger spatiotemporal patterns in order to understand the relationship between dynamical patterns and the scale of inquiry, and to determine the mechanisms driving patterns of population distribution and community composition at larger scales.

In many respects, amphibians should represent a

Manuscript received 26 November 1997; revised 18 June 1998; accepted 24 September 1998. good model for melding small and large scale ecological perspectives. There is a strong tradition of small scale experimental study of the ecological processes responsible for larval amphibian community structure. Laboratory, mesocosm, and field studies have led to well supported ideas on the roles of pond hydroperiod, predation, and interspecific competition in determining community composition among breeding ponds (e.g., Morin 1983, Wilbur 1987, Werner and McPeek 1994, Skelly 1995). This experimental work further links trade-offs in individual characteristics to natural distributions and has led a number of authors to cite larval amphibians as a model system in ecology (e.g., Gurevitch and Hedges 1993; Lima 1998).

In addition, amphibians are receiving a great deal of attention from ecologists interested in large scale patterns. This attention has stemmed from (1) the suspicion that amphibians may be organized into metapopulations, and (2) widely reported large scale declines and disappearances of amphibian populations. In the first instance, there is strong circumstantial evidence for the metapopulation as an organizing principle for understanding large scale distributions of pond breed- 
TABle 1. Pond-breeding frogs and salamanders found at the E. S. George Reserve, Michigan, during 1967-1974 and 19881992 surveys.

\begin{tabular}{|c|c|c|c|c|c|}
\hline \multirow[b]{2}{*}{ Order } & \multirow[b]{2}{*}{ Family } & \multirow[b]{2}{*}{ Species } & \multirow[b]{2}{*}{ Common name } & \multicolumn{2}{|c|}{ No. populations } \\
\hline & & & & $67-74$ & $88-92$ \\
\hline \multirow[t]{3}{*}{ Anura } & Bufonidae & Bufo americanus & American toad & 15 & 14 \\
\hline & Hylidae & $\begin{array}{l}\text { Acris crepitans } \\
\text { Hyla versicolor } \\
\text { Pseudacris crucifer } \\
\text { P. triseriata }\end{array}$ & $\begin{array}{l}\text { Blanchard's cricket frog } \\
\text { gray treefrog } \\
\text { spring peeper } \\
\text { Western chorus frog }\end{array}$ & $\begin{array}{r}2 \\
17 \\
23 \\
20\end{array}$ & $\begin{array}{r}0 \\
21 \\
23 \\
14\end{array}$ \\
\hline & Ranidae & $\begin{array}{l}\text { Rana catesbeiana } \\
R . \text { clamitans } \\
R . \text { pipiens } \\
R \text {. sylvatica }\end{array}$ & $\begin{array}{l}\text { bullfrog } \\
\text { green frog } \\
\text { leopard frog } \\
\text { wood frog }\end{array}$ & $\begin{array}{r}4 \\
11 \\
5 \\
16\end{array}$ & $\begin{array}{r}4 \\
10 \\
6 \\
20\end{array}$ \\
\hline \multirow[t]{3}{*}{ Caudata } & Ambystomatidae & $\begin{array}{l}\text { Ambystoma laterale } \dagger \\
\text { A. maculatum } \\
\text { A. tigrinum }\end{array}$ & $\begin{array}{l}\text { blue-spotted salamander } \\
\text { spotted salamander } \\
\text { tiger salamander }\end{array}$ & $\begin{array}{l}16 \\
11 \\
11\end{array}$ & $\begin{array}{l}18 \\
12 \\
11\end{array}$ \\
\hline & Plethodontidae & Hemidactylum scutatum & four-toed salamander & 2 & 1 \\
\hline & Salamandridae & Notophthalmus viridescens & red-spotted newt & 3 & 8 \\
\hline
\end{tabular}

Notes: No. populations is the total number of breeding populations found in 32 ponds surveyed by Collins and Wilbur (1979) from 1967 to 1974 and for this study during 1988-1992. Only 25 of the 32 ponds were surveyed for salamanders.

$\dagger$ For the purposes of this survey, individuals of the polyploid species Ambystoma tremblayi were not distinguished from A. laterale.

ing amphibians (Gill 1978, Harrison 1991, SjogrenGulve 1994). Many amphibian species breed in insular bodies of water. After undergoing aquatic larval development, emerging juveniles typically move into adjacent terrestrial habitat and most return to breed in their natal pond. As a result populations are centered around breeding habitats, and those populations are linked by low rates of dispersal. Amphibians are also noted for their high frequency of cohort failure, often connected to climate driven variation in pond hydroperiod (a potential localized stochastic factor leading to population extinction). If metapopulation structure is important to the dynamics of populations, then extinctions and colonizations should be frequent events. Most current metapopulation models (e.g., Hanski 1994) also suggest that proximity to source populations should influence the likelihood of colonization (isolated habitats are less likely to be colonized) and extinction (isolated habitats are less likely to be rescued from extinction by dispersing individuals).

In the second instance, amphibians have become unlikely icons for conservationists since reports of population declines and disappearances began surfacing nearly a decade ago. Despite intense interest and debate, there is still little consensus among scientists regarding the mechanisms responsible for declines for most species (e.g., Sarkar 1996). While some population declines and disappearances appear to be catastrophic, it is difficult to judge the severity of many declines because it is unclear to what extent amphibian populations typically fluctuate in abundance or presence-absence at a site (Pechmann and Wilbur 1994).

In this study we consider the distributional patterns of 14 species of amphibians among 37 ponds across a 540-ha area. Further, we assess changes in these dis- tributional patterns over a span of $25 \mathrm{yr}$ by comparing our results collected between 1988 and 1992 with those collected between 1967 and 1974 by Collins and Wilbur (1979). We use these data to address several questions. First, what are the patterns of amphibian distributions at larger spatiotemporal scales? Second, how common are population colonizations and extinctions? Third, based on these observations what are the likely mechanisms underlying the patterns and dynamics of amphibian distributions?

\section{Study Area And the Amphibian Assemblage}

The E. S. George Reserve (hereafter ESGR) is an area of $\sim 540$ ha that has been administered as a restricted access preserve by the University of Michigan since 1930 (see Collins and Wilbur [1979] for fuller description). It is located $\sim 40 \mathrm{~km}$ northwest of Ann Arbor, Michigan $\left(42^{\circ} 28^{\prime} \mathrm{N}, 84^{\circ} 00^{\prime} \mathrm{W}\right)$ in a region dominated by interlobate morainic physiography. Aquatic habitats include a number of kettlehole ponds, swamps, marshes, and Sphagnum bogs.

Fourteen species of amphibians have been recorded breeding in the aquatic habitats of the ESGR (Table 1). These include representatives of three frog families (Bufonidae, Hylidae, Ranidae) and three salamander families (Ambystomatidae, Plethodontidae, Salamandridae). Species vary widely in life history attributes (e.g., breeding phenology, larval period), yet all share a complex life cycle with an aquatic larval stage followed by a (usually) more terrestrial adult stage. Strictly terrestrial amphibians (Plethodon cinereus) were not included in the survey. For purposes of this study, the salamander species Ambystoma tremblayi was not distinguished from A. laterale. 


\section{Methods}

Between 1988 and 1992 we assayed presence and absence of amphibian populations in 37 ponds. Following the methods used by Collins and Wilbur (1979) we defined a breeding population by the presence of at least one of the following during at least one year: eggs, larvae, metamorphs, amplectant/breeding adults, or chorusing males (frogs). In order to represent evidence of a breeding population a chorus needed to be sustained during the breeding period for the species in question (a few animals calling sporadically was insufficient evidence by itself).

We collected information on amphibian distributions during visits to each pond spread out over the duration of the 1988-1992 survey. Over this period, we averaged $>32$ visits to each pond for a total of nearly 1200 visits completed during the survey. Visits began in March when spring breeding species moved into ponds and extended into July to cover the breeding phenology of all resident species. All ponds were visited during at least three years and most (23 ponds) were visited during all five years. We undertook two categories of visits: chorusing visits and sampling visits.

A primary goal of chorusing visits was to assay the presence of chorusing male frogs. These visits were timed in order to catch peak breeding periods of ESGR species (e.g., most chorusing visits occurred on wet nights spread across the breeding periods of the resident species). Many of these visits focused primarily on listening for chorusing frogs at a pond for 5-15 min. However, during $\sim 40 \%$ of all chorusing visits we also entered the pond to look for adults, amplectant pairs, and eggs of breeding frogs and salamanders. Such visits typically lasted $15-60 \mathrm{~min}$. Each of the 37 ponds received an average of 22 chorusing visits between 1988 and 1992.

We also completed sampling visits in each of the ponds we surveyed. All sampling visits included 15$60 \mathrm{~min}$ of dipnetting. During these visits we also recorded any chorusing activity. Dipnetting involved sweeping a dipnet through representative areas of a pond, recovering and identifying amphibian larvae on the spot, or preserving representative specimens in $70 \%$ $\mathrm{EtOH}$ for later identification in the laboratory. During the 5-yr survey we also pipe sampled 18 of the 37 ponds. Each of these ponds were pipe sampled at least three times. Pipe sampling is a method of estimating densities of larval amphibians (e.g., Skelly 1996). A pipe sampler is a $0.3 \mathrm{~m}$ diameter $\times 1.0 \mathrm{~m}$ long steel pipe that is driven into the benthic substrate. The trapped volume of water is then repeatedly netted to recover organisms. Typically, between 10 and 70 pipe samples were taken in each pond sampled. Seven large ponds with well developed pelagic zones were also seined with a $2 \times 7.5 \mathrm{~m}$ seine during the survey. These ponds were seined at least twice during this period; at each seining two hauls were made. Between 1988 and
1992 we performed an average of 10 sampling visits in each of the 37 ponds we followed.

Sampling effort was not equivalent among ponds during our survey. In general, ponds receiving relatively few visits were small ( $\leq 500 \mathrm{~m}^{2}$ surface area) and those visits tended to last for shorter periods than those of larger ponds. Overall however, just three ponds received $<15$ visits each between 1988 and 1992. Finally, there were two larger ponds (East Marsh, Southwest Swamp) that we were unable to survey for salamanders. Therefore, the total sample size for 1988-1992 salamander distributions is 35 ponds.

We evaluated the effectiveness of our sampling regime by analyzing the accumulation of new distributional records during the course of the 1988-1992 survey. If the number of new records approaches an asymptote it may be concluded that, within the limits of the techniques being applied, the survey has been successful in uncovering virtually all of the populations present. Of a total of 202 distributional records documented by the conclusion of 1988-1992 survey, $94 \%$ had been recorded by the third year (1990) and just three new records were found during the final year (1992). Two of the novel 1992 records were for conspicuously calling frog species (Hyla versicolor, Bufo americanus). We conclude, therefore, that we employed adequate sampling intensity to uncover patterns of presence and absence during our 5-yr survey period.

A primary objective of our survey was to compare amphibian distributions we recorded with those determined by Collins and Wilbur (1979). In large part, we based our survey approach on the methods of Collins and Wilbur, who sampled 32 of the same ponds between 1967 and 1974. Collins and Wilbur do not report sampling effort from their 8-yr survey. However, discussions with them suggest that they also repeatedly visited the ponds they surveyed using a comparable array of techniques and at a comparable sampling intensity (J. Collins and H. Wilbur, personal communication). This impression is confirmed by records of specimens collected from surveyed ponds and deposited with the Division of Herpetology of the Museum of Zoology at the University of Michigan and by publications based on their research from that time period (Wilbur 1971, 1972, Wilbur and Collins 1973, Collins 1975, 1979, Collins and Wilbur 1979).

Changes in a species' distribution between the two surveys was assessed using Jaccard's coefficient of similarity (Jaccard's coefficient $=c /(a+b-c)$, where $a=$ number of ponds occupied by the species during the 1967-1974 survey, $b=$ number of ponds occupied during the 1988-1992 survey, and $c=$ number of ponds occupied during both surveys). This coefficient ranges from 0.0 if a species occupied no ponds in common between surveys (complete turnover in distribution) to 1.0 if a species bred in the same set of ponds during both surveys (no turnover).

During the 1988-1992 survey, we categorized ponds 
TABle 2. Number of populations of 14 amphibian species in 37 ponds on or near the E. S. George Reserve, $1988-1992$. Blanks denote zero populations present in that pond type.

\begin{tabular}{|c|c|c|c|c|c|}
\hline \multirow[b]{2}{*}{ Species } & \multicolumn{3}{|c|}{ No. open-canopy ponds } & \multicolumn{2}{|c|}{ No. closed-canopy ponds } \\
\hline & $\begin{array}{c}\text { Permanent } \\
(N=7)\end{array}$ & $\begin{array}{l}\text { Intermediate } \\
(N=11)\end{array}$ & $\begin{array}{l}\text { Temporary } \\
(N=8)\end{array}$ & $\begin{array}{l}\text { Intermediate } \\
(N=5)\end{array}$ & $\begin{array}{c}\text { Temporary } \\
(N=6)\end{array}$ \\
\hline Rana catesbeiana & 4 & & & & \\
\hline$R$. clamitans & 7 & 6 & & & \\
\hline$R$. pipiens & 4 & 4 & & & \\
\hline$R$. sylvatica & 1 & 9 & 7 & 5 & 1 \\
\hline Hyla versicolor & 6 & 11 & 8 & 1 & \\
\hline Pseudacris crucifer & 6 & 11 & 7 & 3 & \\
\hline P. triseriata & 1 & 9 & 8 & 1 & \\
\hline Notophthalmus viridescens & 3 & 5 & 1 & & \\
\hline Bufo americanus & 5 & 7 & 4 & 1 & \\
\hline Ambystoma laterale & & 10 & 8 & 5 & 3 \\
\hline A. maculatum & & 7 & 3 & 4 & 1 \\
\hline A. tigrinum & 2 & 5 & 1 & 4 & 1 \\
\hline Hemidactylum scutatum & & & 2 & & \\
\hline Acris crepitans & & & & & \\
\hline
\end{tabular}

Notes: Ponds have been placed into five categories based on their hydroperiod and the presence or absence of an overhead forest canopy. Following Collins and Wilbur (1979), a population presence was defined as the presence of at least one of the following during $\geq 1 \mathrm{yr}$ : eggs, larvae, metamorphs, amplectant adults, or chorusing males (for frog species). Total numbers of populations presented in this table do not match totals in Table 1 because Table 1 lists only populations found in the subset of 32 ponds also surveyed by Collins and Wilbur (1979).

based on their history of drying and presence of overhead forest canopy cover. Ponds were denoted permanent if they held water for the entire 5-yr period. Temporary ponds dried each year. Intermediate ponds dried some years but not others. Overhead forest canopy cover was defined as closed if the pond was situated in a stand of trees (Quercus, Carya, and Acer in most cases) whose canopies interdigitated above the entire pond basin; otherwise it was denoted as open. Little direct sunlight reaches the surface of closed-canopy ponds once trees have leafed out during May.

We also used historical information to document changes in pond attributes between surveys. An aerial photograph of the ESGR taken during the first survey (2 August 1970) was used to compare canopy cover at that time with our measure of 1988-1992 canopy cover. Data on drying times of seven ponds from 1971-1974 (Collins 1975) allowed us to compare hydroperiod of these individual ponds between survey periods. The drying time of each pond was converted to a score that ranged from zero if the pond dried during the first quartile of May to 24 if the pond dried during the last quartile of October. Ponds that did not completely dry were given a score of 25 . We used analysis of covariance (ANCOVA) to determine whether the timing of pond drying varied between survey periods at a given amount of rainfall (measured as total precipitation between January and June recorded at Ann Arbor, Michigan).

For each species we also calculated an index of range within the ESGR. The spatial extent of a species' distribution was estimated as the least convex polygon surrounding the locations of each of the breeding ponds. Breeding pond locations were represented by grid cell locations from the 1963 ESGR grid $(100 \times$
$100 \mathrm{~m}$ grid cells; see Collins and Wilbur [1979]). For two species, Acris crepitans and Hemidactylum scutatum, least convex polygons could not be calculated because the species was represented by two populations or less. When there were two populations, range was calculated as a rectangle of unit width $(100 \mathrm{~m})$ stretching from the location of one pond to the other. In the single case where a species was represented by one population, range was estimated as the area of a single grid cell $(100 \times 100 \mathrm{~m})$.

\section{RESULTS}

\section{Species distributions}

During the 1988-1992 survey we categorized 37 ponds according to both pond hydroperiod (temporary, intermediate, permanent) and overhead forest canopy (open, closed). We identified 6 temporary, closed-canopy ponds, 5 intermediate, closed-canopy ponds, 8 temporary, open-canopy ponds, 11 intermediate, open-canopy ponds, and 7 permanent, open-canopy ponds. There were no permanent, closed-canopy ponds.

When ponds were categorized according to hydroperiod and forest canopy cover, a number of distributional patterns emerged (Table 2). Between 1988 and 1992, the average species was present in about three of the five pond types. The degree of specialization ranged from two species found in a single pond type (Rana catesbeiana, permanent, open-canopy ponds; Hemidactylum scutatum, temporary, open-canopy ponds), to two species found in all five pond types (Rana sylvatica, Ambystoma tigrinum). However, none of the species were found in all ponds on the ESGR (Pseudacris crucifer was the most widespread species, with 27 populations in the 37 ponds) and no single 
TABLE 3. Probabilities of significant association from likelihood ratio tests assessing presence and absence of amphibian species among ponds that vary in hydroperiod and forest canopy.

\begin{tabular}{lccc}
\hline \hline & & Pond attributes & \\
\cline { 2 - 4 } \multicolumn{1}{c}{ Species } & Hydroperiod & Canopy & $\begin{array}{c}\text { Hydroperiod } \\
\text { and canopy }\end{array}$ \\
\hline Bufo americanus & 0.154 & 0.002 & 0.007 \\
Hyla versicolor & 0.337 & $<0.001$ & $<0.001$ \\
Pseudacris crucifer & 0.050 & $<0.001$ & $<0.001$ \\
P. triseriata & 0.073 & $<0.001$ & $<0.001$ \\
Rana clamitans & $<0.001$ & 0.001 & $<0.001$ \\
R. pipiens & 0.004 & 0.011 & 0.002 \\
R. sylvatica & 0.002 & 0.537 & $<0.001$ \\
Ambystoma laterale & $<0.001$ & 0.887 & 0.001 \\
A. maculatum & 0.004 & 0.834 & 0.006 \\
A. tigrinum & 0.049 & 0.493 & 0.007 \\
Notophthalmus viridescens & 0.048 & 0.004 & 0.007
\end{tabular}

Notes: Hydroperiod was divided into three categories based on the frequency of pond drying: permanent ponds retained water for the entire 1988-1992 survey; intermediate ponds dried during some years between 1988 and 1992, but not during others; temporary ponds dried each year between 1988 and 1992. Forest canopy was defined as open unless the crowns of trees interdigitated above the entire pond basin. A significant association suggests that the distribution of the species is not independent of the tested pond attribute. Three of the 14 species surveyed were not analyzed because of insufficient presences (Acris crepitans, Hemidactylum scutatum, and Rana catesbeiana).

pond type was inhabited by all 14 species. When species richness was calculated across pond types, four of the five categories contained a majority of the 14 species (permanent, open-canopy: 10 species; intermediate, open-canopy: 11 species; temporary, open-canopy: 9 species; intermediate, closed-canopy: 8 species). In contrast, just three species were found in temporary, closed-canopy ponds.

Patterns of species' distribution among pond types were analyzed using likelihood ratio tests. For each species, three tests were conducted: the first was used to determine whether species were randomly distributed across all five hydroperiod-canopy categories, the second whether species were randomly distributed across the three pond hydroperiod categories, and the third whether species were randomly distributed across the two canopy categories. Three species were not included in these analyses because of insufficient number of populations (A. crepitans, H. scutatum, R. catesbeiana). While each of the 11 species analyzed exhibited nonrandom distributions across the five hydroperiod-canopy cover categories (Table 3, likelihood ratio tests, $P<0.05$ in each case), there was large variation in the degree of significance. Species with higher $P$ values tended to be those with fewer populations spread over a larger number of pond categories (e.g., Ambystoma tigrinum).

When the analysis was collapsed to consider only hydroperiod categories, distributions of most species differed significantly among permanent, intermediate, and temporary ponds (Table 3 ). The most notable exceptions included two species that can be found broadly distributed in ponds of all three permanence categories (Bufo americanus, Hyla versicolor). Distribution also was nonrandom with respect to canopy cover for the majority of the (7 of 11 species. Distribution was positively associated with open-canopy ponds in B. amer- icanus, H. versicolor, Pseudacris crucifer, P. triseriata, $R$. clamitans, $R$. pipiens, Notophthalmus viridescens. The remaining species were randomly distributed with respect to canopy cover ( $R$. sylvatica, A. laterale, A. maculatum, A. tigrinum).

In several cases, significant associations with hydroperiod and canopy gradients reflected sharp boundaries in the distributional patterns of species. For example, two of the three ranid species analyzed ( $R$. clamitans, $R$. pipiens) were never found breeding in temporary ponds, while two of the three ambystomatid species $(A$. laterale, $A$. maculatum) were never found in permanent ponds. A number of species never, or virtually never, occurred in closed-canopy ponds (e.g., B. americanus, $H$. versicolor, $N$. viridescens, $R$. clamitans, $R$. pipiens). There were no species with distributions restricted to closed-canopy ponds, but three species were most prevalent in intermediate, closed-canopy ponds compared to the other pond types ( $R$. sylvatica, A. laterale, $A$. maculatum; Table 3).

\section{Changes in species' distributions between surveys}

The amphibian assemblage on the ESGR experienced dramatic changes between survey periods. The distribution of each of the 14 species changed, and similarity of distributions among ponds compared between surveys averaged just 0.53 (measured as Jaccard's coefficient; Fig. 1). While for some species, change was moderate (e.g., R. clamitans experienced a single population extinction), for most species, distributional change was pronounced (e.g., 5 extinction and 5 colonization events by $P$. crucifer). On average, each species experienced 5.3 distributional changes (colonizations plus extinctions). Across all species, colonizations were slightly more numerous than extinctions (40 colonizations vs. 34 extinctions). Interestingly, most species experienced little net change in 


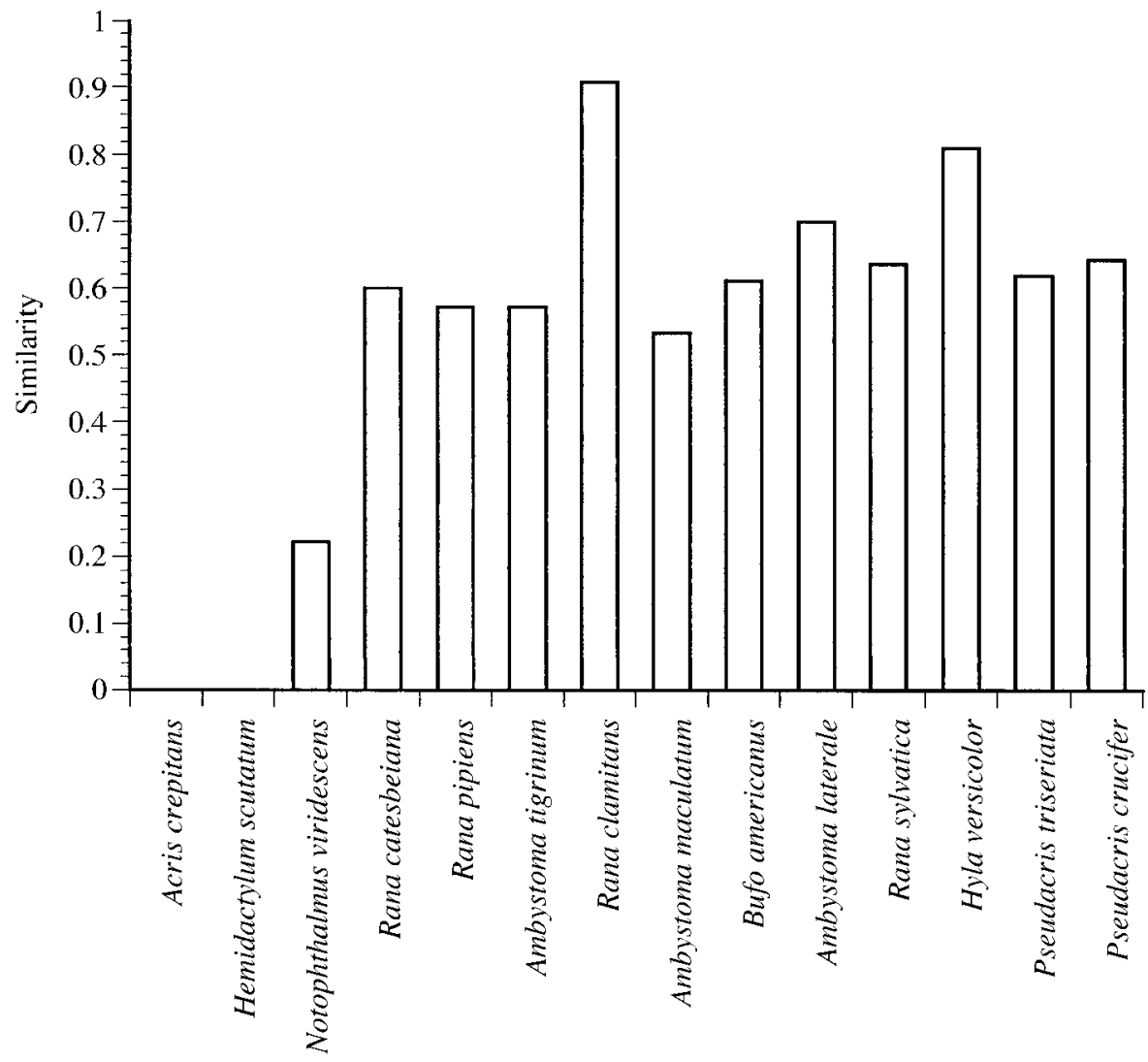

FIG. 1. Similarity of amphibian breeding distributions measured in 32 ponds at the E. S. George Reserve, Michigan: 1967-1974 vs. 1988-1992. Similarity was measured using Jaccard's coefficient, which ranges from 0 if species bred in entirely different ponds during the two surveys to 1 if a species bred in exactly the same complement of ponds during both surveys. Species are arranged from left to right according to the number of populations (from fewest to greatest) at the time of the 1967-1974 survey.

total number of populations. Net change was less than two populations for 10 of the 14 species (Fig. 2). Exceptions included Hyla versicolor and Rana sylvatica (increase of four populations), $N$. viridescens (increase of five populations) and $P$. triseriata (decrease of six populations). Acris crepitans (only two populations initially) became locally extinct on the ESGR during a severe drought in 1971 (Collins and Wilbur 1979). This species is still present in areas near the ESGR (S. Cortwright and D. Skelly, personal observations).

\section{Changes in pond attributes and species distributions}

We analyzed the patterns of distributional changes between surveys with respect to pond attributes. Our analyses suggested that ponds had changed in terms of both canopy cover and hydroperiod between surveys. Comparisons with a 1970 aerial photograph revealed that, of the 11 ponds found under closed canopy during the recent survey, at least nine had open canopies during the first survey. There were no instances of closedcanopy ponds becoming open-canopy ponds. The striking changes in canopy overgrowth echo a larger successional trend evident on the ESGR (see Discussion).
Comparisons between recent and historical pond drying records also suggested that ponds were drying earlier during the recent survey. Using a pond-by-pond analysis, it appears that drying may be occurring $\geq 2.5$ wk earlier with a given amount of rainfall (ANCOVA: $n=7$ ponds, df $=1, F=18.87, P<0.001)$.

These patterns indicate that many ponds may have been substantially different habitats during the first survey. Using present day pond categorizations, we asked whether the tendency for population colonization and extinction varied with pond type. A likelihood ratio test revealed a strong relation between population status (stable, invaded, went extinct, never present) and pond type $\left(\chi^{2}=72.1\right.$, df $\left.=12, P<0.001\right)$. Overall, open-canopy ponds tended to gain species between surveys, while ponds presently under closed canopy tended to lose species (Fig. 3). Particularly striking were the extinctions that occurred in temporary, closed-canopy ponds. Between surveys, there were no colonizations and two-thirds of the populations present went extinct in this pond-type category. For some species it appears that colonizations and extinctions were restricted to particular pond types. A number of species 


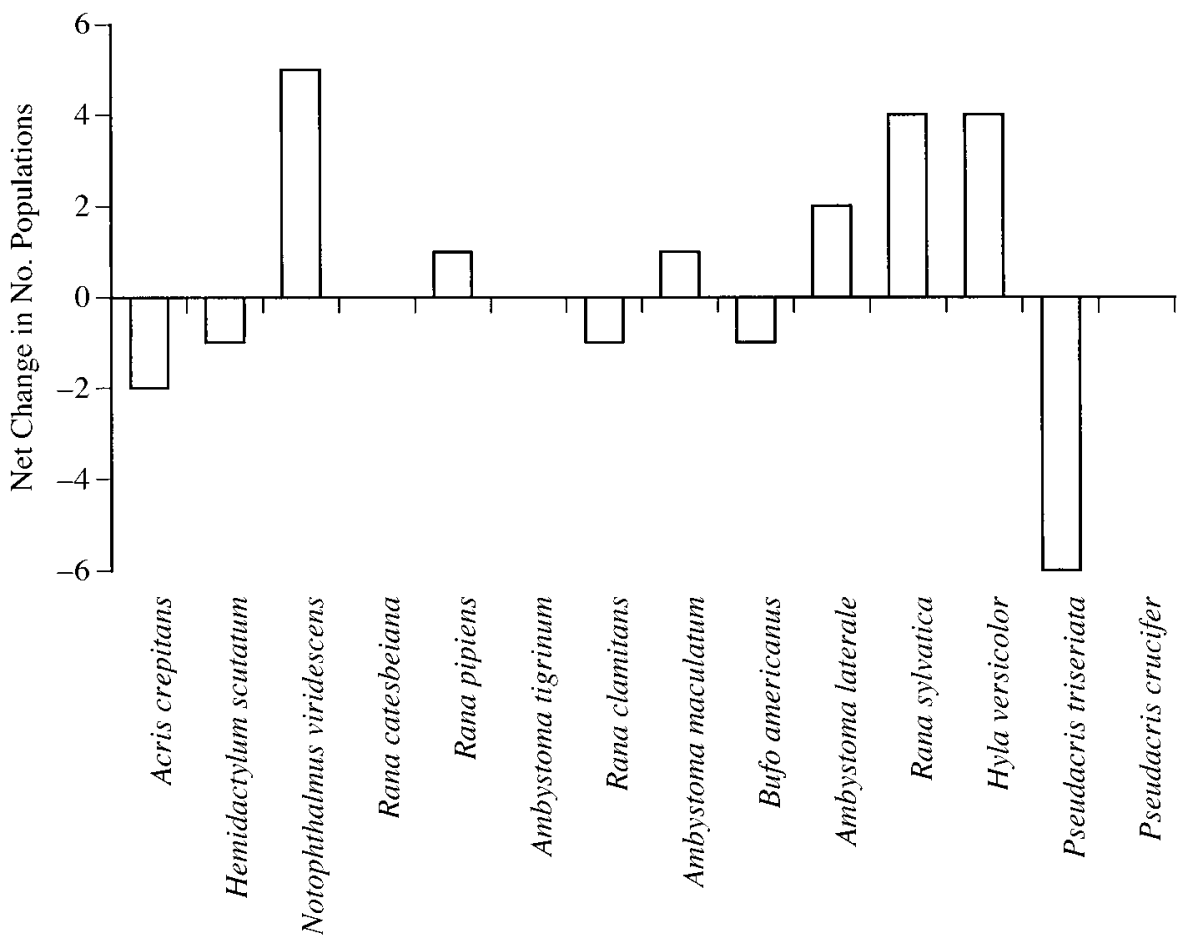

FIG. 2. Net change in the number of breeding populations between two surveys (1967-1974 vs. 1988-1992) at the E. S. George Reserve, Michigan. The average species experienced about five colonizations plus extinctions between the two surveys. Overall, there were 40 population colonizations and 34 population extinctions. Species are arranged left to right according to the number of populations (from fewest to greatest) at the time of the 1967-1974 survey.

went extinct primarily in ponds currently under closed canopy (i.e., Pseudacris crucifer, Pseudacris triseriata, Ambystoma laterale, and Ambystoma maculatum). $P$. crucifer tended to invade permanent ponds while $A$. maculatum and $N$. viridescens tended to move into intermediate ponds with open canopies.

\section{Spatial patterns of colonization and extinction}

We quantified the spatial extent of species distributions during both surveys as well as the spatial pattern of population changes. On average, a species' range (1988-1992) covered roughly $60 \%$ of what it would if the species occupied all surveyed habitats (32 surveyed ponds for frogs and 25 surveyed ponds for salamanders). For half of the species, range during the recent survey covered more than three-quarters of the possible area, with values as high as 95\% (Ambystoma laterale, $P$. crucifer). Despite the number of population colonizations and extinctions, there was little overall change in spatial extent of most species between surveys. However, three species greatly increased in range by the time of the recent survey. $N$. viridescens experienced a net increase of five populations between surveys and a 25 -fold increase in range. This species was formerly restricted to three populations in the center of the ESGR, but colonized several ponds in the northwestern corner. If source individuals came from within the ESGR, the minimum dispersal distance was
$>1000$ m. Similarly, Ambystoma tigrinum greatly increased its range by colonizing a set of three ponds in the northeastern corner of the reserve. Finally, $R$. $c a$ tesbeiana greatly increased its range by colonizing a single pond in the northwestern corner of the ESGR.

For each species we used a Mantel test to determine whether population status was autocorrelated in space (Legendre and Fortin 1989). Population status of a species in a pond was defined as: never present, present 1967-1974 only (population went extinct prior to second survey), present 1988-1992 (population invaded since first survey), and present during both surveys. Significant autocorrelations indicate a nonrandom clustering of population status in space (e.g., if all colonizations tended to occur near one another). Just two of the 14 species, Ambystoma maculatum and A. tigrinum, exhibited spatial autocorrelation in population status. For A. tigrinum this result stems, in part, from the cluster of colonizations in the northeastern part of the ESGR. In contrast, A. maculatum went extinct exclusively in ponds found in the northeastern region of the ESGR.

We also examined the relationship between population status (as defined in the preceding paragraph) and isolation. Isolation was defined as the distance from a given pond to the nearest potential source population of a species (as indicated by the 1967-1974 survey). Analysis of variance revealed significant variation in 


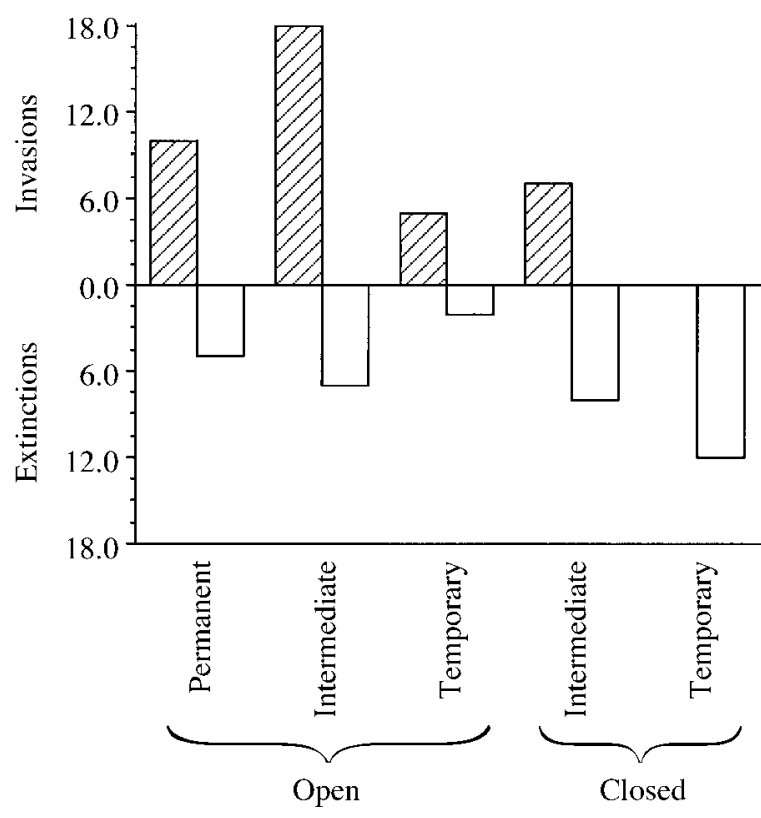

Pond Permanence and Canopy

FIG. 3. The total number of population colonizations and extinctions observed in each of five pond types categorized according to pond hydroperiod and overhead forest canopy. Across all 14 species there were 40 colonizations and 34 extinctions. There were a total of eight temporary, open-canopy ponds, 11 intermediate, open-canopy ponds, seven permanent, open-canopy ponds, five intermediate closed-canopy ponds, and six temporary, closed-canopy ponds (32 ponds overall).

isolation among categories of population status $(\mathrm{df}=$ 3 , ss $=8125708, F=21.6, P<0.0001$; Fig. 4). Ponds with stable populations tended to be closest to potential source populations (mean $\sim 150 \mathrm{~m}$ from the nearest source population). Ponds in which a species was absent during the first survey, but which had been colonized by the time of the second survey (mean $\sim 400$ $\mathrm{m}$ ), and ponds in which populations had gone extinct between surveys (mean $\sim 300 \mathrm{~m}$ ) tended to be intermediate in isolation. Ponds never occupied by a species tended to be farthest, on average, from potential source populations (mean $\sim 500 \mathrm{~m}$ ). We used a priori contrasts to evaluate two specific predictions: (1) ponds that were never invaded were more isolated than those that were colonized between surveys; and (2) ponds from which populations went extinct were more isolated than those where populations persisted. While both trends were in the predicted directions (Fig. 4), uncolonized ponds were not more isolated than those that were colonized (df $=56, t=1.442, P=0.155$ ). The contrast between extinct and stable populations was marginally nonsignificant $(\mathrm{df}=36, t=1.948, P=0.059)$.

\section{DISCUSSION}

It is clear from long term observations of ESGR amphibians that certain environmental gradients are strongly related to overall patterns of distribution and composition of the amphibian assemblage. Specifically, we found that variation in hydroperiod, overhead forest canopy, and isolation from source populations are all correlated with patterns of population presence and absence among ponds. We also found that colonizations and extinctions are surprisingly common among the 14 species studied. Fully $22 \%$ of the populations documented by Collins and Wilbur during 1967-1974 were extinct by the time the recent survey began in 1988 . Colonizations were slightly more numerous. These dynamics were observed in the absence of any major declines in numbers in individual species. Our evidence suggests that the pronounced dynamics in species distributions may be causally linked to the environmental gradients we measured. In the remainder of the Discussion we evaluate potential mechanisms underlying distributional patterns in amphibians and place our findings in a more general context.

Hydroperiod.-The hydroperiod, or pond permanence, gradient is a well known axis delimiting distributions of many freshwater organisms (reviewed by Wellborn et al. [1996]). In this study we found that most amphibians were distributed nonrandomly among ponds categorized by their tendency to dry. Some species were most commonly found in temporary ponds, some in permanent ponds, while others were most frequently present in ponds intermediate in their drying tendency. These findings are consistent with the conclusions of an earlier survey of the ESGR by Collins and Wilbur (1979), along with studies of amphibians at other sites (Heyer et al. 1988, Gascon 1991, Hecnar and M'Closkey 1996).

For amphibians and other freshwater animals pond hydroperiod provides a strong constraint on the pool of species that can successfully breed in ponds. Am-

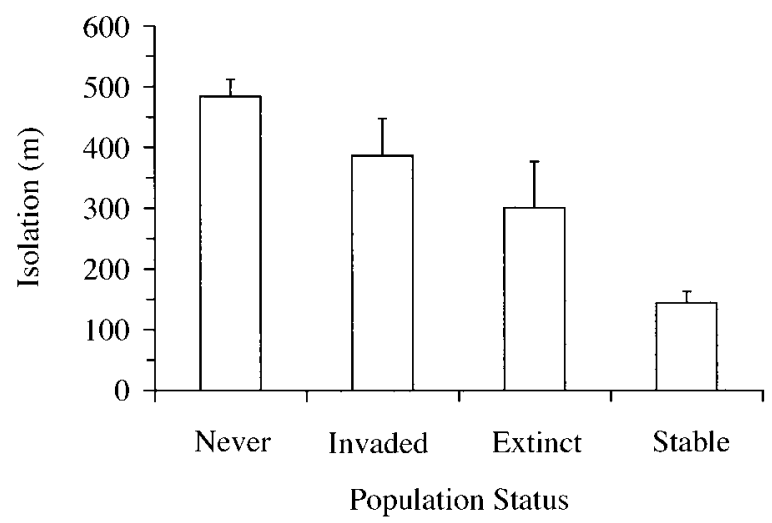

FIG. 4. Isolation of ponds according to population status during the 1967-1974 and 1988-1992 surveys. Population status was defined as follows: not present during either survey (Never), present 1988-1992 only (Invaded), present 19671974 only (Extinct), present during both surveys (Stable). Isolation is the distance to the nearest source population (1967-1974) averaged across all species. Data bars represent means +1 SE. 
phibians with longer larval periods are restricted to relatively permanent water; only species that complete larval development rapidly are able to utilize ponds with shorter hydroperiods (reviewed by Wellborn et al. 1996). In the extreme, two ESGR species, $R$. clamitans and $R$. catesbeiana facultatively or obligately overwinter as larvae. Neither of these species was ever found breeding in temporary ponds. Other species that do not overwinter but that breed in the late spring and early summer (e.g., N. viridescens) require aquatic habitats that remain filled until late in summer and tend to be found in ponds intermediate in permanence.

While these examples emphasize the absolute limits on developmental time imposed by drying events, the pattern of pond drying can have other subtler, but no less critical, consequences for larval amphibians. For example, compared with temporary ponds, ponds with longer hydroperiods typically have more and larger predators (Woodward 1983, Skelly 1995, Smith and Van Buskirk 1995). In a field experiment at the ESGR, Skelly (1995) showed that Pseudacris triseriata, a species that typically does not breed in permanent ponds, survived extremely poorly in the presence of the predators in permanent ponds. These results are representative of several studies showing that fish and other predators restricted to relatively permanent water have strong impacts on the performance and distribution of larval amphibians (Brockelman 1969, Bronmark and Edenhamn 1994, Werner and McPeek 1994, Smith and Van Buskirk 1995).

Further, a large body of work is gradually revealing the mechanistic details linking individual phenotype and larval performance across the hydroperiod gradient. These studies suggest that aspects of larval behavior, particularly activity rates, that promote rapid growth and development also elevate predation risk (Lawler 1989, Skelly 1992, 1995, Smith and Van Buskirk 1995, Werner and Anholt 1993). It follows that evolutionary responses to contrasting environments should reinforce the specialization imposed by such trade-offs. As an example, ranids have diverged in behavioral responses to predators (Werner 1991). Species such as $R$. catesbeiana larvae that typically live with fish are relatively immune to fish predation because they are unpalatable. However in fishless habitats the high rates of activity characteristic of $R$. catesbeiana larvae make them extremely vulnerable to invertebrate predators. Conversely, ranids that typically live in the absence of fish rely on behavioral responses to predators that are largely ineffective defenses against fish predators. The intensity of the effects of both drying and predation seem to limit most amphibian species to a relatively narrow swath of the hydroperiod gradient; true generalists are rare (Wellborn et al. 1996, Skelly 1997). It may not be a coincidence that one of the amphibian species found breeding randomly among pond hydroperiod categories (B. americanus) is able to develop rapidly and also is unpalatable to many predators (Wilbur 1977, Kruse and Stone 1984).

Canopy. - The 1988-1992 survey revealed a second, important environmental gradient at the ESGR: forest canopy. Resident amphibians can be divided into two groups based on their distribution relative to forest canopy cover over breeding ponds. The majority of the fauna is virtually never present in closed-canopy ponds. A smaller subset of species including one frog and three salamander species is frequently found in closed-canopy ponds. While natural historians have often linked these latter species with "woodland" ponds (Wright and Wright 1949, Conant and Collins 1991), the associations have rarely been quantified. Interestingly, species often denoted as breeding in closed-canopy ponds are found with practically equal frequency in open-canopy ponds (Table 2).

Compared with the many studies of pond hydroperiod effects, there has been far less research into the mechanisms underlying distributional patterns across the canopy gradient (but see Bussler [1982]). Preliminary studies suggest that, as with the hydroperiod gradient, both physical and biotic factors may be important and that trade-offs may underlie tolerances to the different conditions in open- vs. closed-canopy ponds. In particular, closed-canopy ponds may be challenging environments because of lower light, lower dissolved oxygen concentrations, and lower temperatures (Werner and Glennmeier 1999). Werner and Glennmeier (1999) found that closed-canopy ponds at the ESGR have dissolved oxygen concentrations of $\leq 2 \mathrm{mg} / \mathrm{L}$ during the summer. These concentrations are lower than those shown to induce anuran larvae to bob at the surface for oxygen (Wassersug and Seibert 1975). Coupled with these physical differences are apparent differences in food resources between closed- and open-canopy ponds (D. K. Skelly, L. K. Freidenburg, and J. M. Kiesecker, unpublished data). In these ponds it appears that variation in food resources across the canopy gradient may have important effects on growth and survivorship of some anuran species (Werner and Glennmeier, 1999). Transplant experiments reveal that growth and survivorship can be much higher in openvs. closed-canopy ponds. Poor performance in closedcanopy ponds can be partially ameliorated by addition of high quality food. Further research will be required to elucidate the suite of traits that allow some species to generalize across this gradient while restricting most species to open-canopy ponds.

Temporal changes in hydroperiod and canopy.-The long tradition of ecological research at the ESGR affords an unusual opportunity to examine associations between patterns of amphibian distribution and attributes of pond habitats. Since agricultural abandonment early in this century, forest cover has greatly increased at the ESGR. In 1937 forest accounted for 30\% of land area (Roller 1974). By the time of the first survey (1970) this figure had increased to 47\% (Roller 1974) 
and has now climbed to $67 \%$ (T. Howard, personal communication). In addition to altering available habitat for terrestrial adults of many amphibian species (e.g., Fitch 1982), forest succession directly impacts ponds as trees gradually grow and shade pond basins. Closed canopies were found over just a couple of ponds during the 1967-1974 survey. By the time of our survey nearly one-third of ponds were under closed canopies. Although closed-canopy ponds still form a minority of ponds, they were associated with a majority of extinctions between surveys. Two-thirds of the populations present 1967-1974 in temporary, closed-canopy ponds were extinct by the time of the 1988-1992 survey. Of the six ponds in this category during the recent survey, three supported no amphibians at all and just a single pond supported more than one amphibian species.

In addition to impacts on ponds due to shading, the growth of forests also likely increased water demand for evapotranspiration (an effect documented in a number of catchment experiments reviewed by Bosch and Hewlett [1982]). Among the ESGR ponds for which historical data are available (Collins 1975), it appears that hydroperiod has declined since the first survey. The magnitude of the estimated effect (drying $\leq 2.5 \mathrm{wk}$ earlier given the same amount of rainfall), is large enough to suggest that decreased hydroperiods could impact amphibian populations.

Spatial effects. - We analyzed the role of spatial distribution of habitats by evaluating isolation of ponds from potential source populations. Our results were consistent with the idea that distributional patterns are influenced by proximity to neighboring populations (Fig. 4). Ponds in which species populations were present during both surveys tended to be closer to potential source populations than ponds that were never occupied by a species during either survey. We found some support for the hypothesis that the likelihood of colonization and extinction might be influenced by the degree of habitat isolation, as assumed by many metapopulation models. Although the metapopulation has been nominated as a likely framework for understanding large scale amphibian distributions (e.g., Harrison 1991), there have been relatively few empirical studies that bear on the role of spatial distribution of amphibian breeding habitats (Gill 1978, Laan and Verboom 1990, Mann et al. 1991, Sjogren-Gulve 1994).

The spatial effects observed among ESGR populations must be considered in the context of the ESGR landscape. The ESGR has few human-constructed barriers to amphibian movement and a high fraction of wetlands (Roller 1974). Consequently, isolation distances are small, on the same order as commonly observed dispersal distances for some of the resident species (e.g., Berven and Grudzien 1990). In addition, at the time of the first survey most amphibians were broadly distributed throughout the landscape. Just a few species had spatially restricted distributions within the ESGR. Given these conditions it is perhaps surprising that there was any statistical signal from spatial effects. Other studies (e.g., Sjogren-Gulve 1994) have found stronger spatial effects when isolation distances are at the scale of several kilometers rather than hundreds of meters (as at the ESGR).

Conclusions. - Small scale experiments have amply documented that environmental factors such as hydroperiod can have strong impacts on the performance of amphibian larvae (e.g., Wilbur 1987). In this study we asked whether such environmental factors, when arrayed as gradients in space and time, can have strong impacts on the distribution of amphibians. Our results allow us to draw the following conclusions:

1) Amphibian distributions are tightly linked to environmental gradients. Hydroperiod, canopy and isolation are each associated with patterns of population distribution.

2) Critical environmental gradients are not fixed in time. With few exceptions (e.g., Gill 1978, SjogrenGulve 1994) amphibian ecologists have not focused on the dynamics of habitats and the consequent impacts on amphibian populations. The results of the ESGR surveys suggest that both hydroperiod and canopy changed substantially in a number of ponds over the course of a 25-yr period.

3) Amphibian distributions can be highly dynamic. The level of population turnover we documented between surveys was surprisingly high. While superficially reminiscent of a classic metapopulation scenario, it appears that deterministic rather than stochastic factors may drive patterns of extinction (Skelly and Meir 1997). Ongoing research is designed to evaluate the hypothesis that dramatic changes in amphibian distributions are related to temporal changes in habitat attributes (e.g., canopy, hydroperiod).

Large scale patterns of amphibian distributions have received a great deal of attention in recent years as reports of declining and disappearing amphibian populations have surfaced from around the world (Blaustein et al. 1994, Pechmann and Wilbur 1994, Sarkar 1996). These reports justifiably triggered alarm. The volatility suggested by our results reinforces the message from long-term studies of single populations (Pechmann et al. 1989, 1991). It appears that instability of amphibian populations that occurs even in the absence of declines will make it difficult to detect declining species without long-term data from many sites.

4) Finally, our results suggest that forest succession is likely to be an important consideration in the longterm dynamics of amphibian populations over much of eastern North America (see also deMaynadier and Hunter [1995]). Regional studies have documented that forest cover has substantially increased following agricultural abandonment at several sites in the eastern United States (Nyland et al. 1986, Goigel Turner and Ruscher 1988, Foster 1995). In Michigan alone, >1.6 million ha of farmland was abandoned between 1910 
and 1959 (Hart 1968). While some of this land has been developed much of it, like the ESGR, has been reverting to forest. This pattern of landscape change may have profound consequences for distributions of amphibians and a wide variety of other freshwater taxa.

\section{ACKNOWLEDGMENTS}

Jim Collins, Francis Evans, and Henry Wilbur have been invaluable sources of information on the history of the ESGR and the first amphibian survey. We thank the many people who helped survey ponds including Tom Slawski, Gary Wellborn, Jeff Moorehead, Mark McPeek, and Maria Ellis. Karen Beard, Micheal Bowers, Kealoha Freidenburg, Peter Hambak, Peter Kareiva, Joe Kiesecker, Andy McCollum, Miguel Pascual, Denis Potvin, Evan Preisser, Kris Rothley, Os Schmitz, and two anonymous reviewers provided helpful comments on earlier versions of the manuscript. Paul Barten provided hydrological references. William Leja introduced us to the German literature on canopy effects. Ron Nussbaum, Jack Haynes, and the maintenance crew provided access to the E. S. George Reserve. D. K. Skelly was supported by funding from the Department of Biology and the Museum of Zoology at the University of Michigan and by a NSF postdoctoral fellowship in environmental biology. E. E. Werner was supported by NSF grants BSR 8796176 and DEB 9119948.

\section{LiterATURe Cited}

Berven, K. A., and T. A. Grudzien. 1990. Dispersal in the wood frog (Rana sylvatica): implications for genetic population structure. Evolution 44:2047-2056.

Blaustein, A. R., D. B. Wake, and W. P. Sousa. 1994. Amphibian declines: judging stability, persistence, and susceptibility of populations to local and global extinctions. Conservation Biology 8:60-71.

Bosch, J. M., and J. D. Hewlett. 1982. A review of catchment experiments to determine the effect of vegetation changes on water yield and evapotranspiration. Journal of Hydrology 55:3-23.

Brockelman, W. Y. 1969. An analysis of density effects and predation in Bufo americanus tadpoles. Ecology 50:632644.

Bronmark, C., and P. Edenhamn. 1994. Does the presence of fish affect the distribution of treefrogs? Conservation Biology 8:841-845.

Brown, J. H. 1995. Macroecology. University of Chicago Press, Chicago, Illinois, USA.

Bussler, H. 1982. Waldgewasser als Lebensraum. Natur und Landschaft 57:128-132.

Collins, J. P. 1975. A comparative study of the life history strategies in a community of frogs. Dissertation. University of Michigan, Ann Arbor, Michigan, USA.

- 1979. Intrapopulation variation in the timing of metamorphosis and the body size at metamorphosis in the bullfrog, Rana catesbeiana. Ecology 60:738-749.

Collins, J. P., and H. M. Wilbur. 1979. Breeding habits and habitats of the amphibians of the E. S. George Reserve, Michigan, with notes on the distribution of fishes. Occasional Papers of the Museum of Zoology, University of Michigan 686:1-34.

Conant, R., and J. T. Collins. 1991. A field guide to reptiles and amphibians of eastern and central North America. Houghton Mifflin Company, Boston, Massachusetts, USA

deMaynadier, P. G., and M. L. Hunter. 1995. The relationship between forest management and amphibian ecology: a review of the North American literature. Environmental Review 3:230-261.

Fitch, H. S. 1982. Resources of a snake community in prairie-woodland habitat of northeastern Kansas. Pages 83-97 in N. J. Scott, Jr., editor. Herpetological communi- ties. U.S. Fish and Wildlife Research Report 313, Washington, D.C., USA.

Foster, D. 1995. Land use history and forest transformations in central New England. Pages 91-110 in M. J. McDonnell and S. T. A. Pickett, editors. Humans as components of ecosystems. Springer-Verlag, New York, New York, USA.

Gascon, C. 1991. Population and community-level analyses of species occurrence of central Amazonian rainforest tadpoles. Ecology 72:1731-1746.

Gill, D. E. 1978. The metapopulation ecology of the redspotted newt, Notophthalmus viridescens (Rafinesque). Ecological Monographs 48:145-166.

Goigel Turner, M., and C. L. Ruscher. 1988. Changes in landscape patterns in Georgia, USA. Landscape Ecology 1:241-251.

Gurevitch, J., and L. V. Hedges. 1993. Meta-analysis: combining the results of independent experiments. Pages 378398 in S. M. Scheiner and J. Gurevitch, editors. Design and analysis of ecological experiments. Chapman and Hall, New York, New York, USA.

Hanski, I. 1994. A practical model of metapopulation dynamics. Journal of Animal Ecology 63:151-162.

Harrison, S. 1991. Local extinction in a metapopulation context: an empirical evaluation. Biological Journal of the Linnean Society 42:73-88.

Hart, J. F. 1968. Loss and abandonment of cleared farm land in the eastern United States. Annals of the Association of American Geographers 58:417-440.

Hecnar, S. J., and R. T. M'Closkey. 1996. Regional dynamics and the status of amphibians. Ecology 77:2091-2097.

Heyer, W. R., A. S. Rand, C. A. Goncalvez da Cruz, and O. L. Peixoto. 1988. Decimations, extinctions, and colonizations of frog population in southeast Brazil and their evolutionary implications. Biotropica 20:230-235.

Kareiva, P., and M. Andersen. 1988. Spatial aspects of species interactions: the wedding of models and experiments. Pages 38-54 in A. Hastings, editor. Community ecology. Springer-Verlag, New York, New York, USA.

Kruse, K. C., and B. M. Stone. 1984. Largemouth bass (Micropterus salmoides) learn to avoid feeding on toad (Bufo) tadpoles. Animal Behavior 32:1035-1039.

Laan, R., and B. Verboom. 1990. Effects of pool size and isolation on amphibian communities. Biological Conservation 54:251-262.

Lawler, S. P. 1989. Behavioral responses to predators and predation risk in four species of larval anurans. Animal Behavior 38:1039-1047.

Legendre, P., and M.-J. Fortin. 1989. Spatial pattern and ecological analysis. Vegetatio 80:107-138.

Levin, S. A. 1992. The problem of pattern and scale in ecology. Ecology 73:1943-1967.

Lima, S. L. 1998. Stress and decision making under the risk of predation: recent developments from behavioral, reproductive and ecological perspectives. Advances in the Study of Behavior 27:215-290.

Mann, W., P. Dorn, and R. Brandl. 1991. Local distribution of amphibians: the importance of habitat fragmentation. Global Ecology and Biogeography Letters 1:36-41.

Morin, P. J. 1983. Predation, competition, and the composition of larval anuran guilds. Ecological Monographs 53: 119-138.

Nyland, R. D., W. C. Zipperer, and D. B. Hill. 1986. The development of forest islands in exurban central New York state. Landscape and Urban Planning 13:111-123.

Pechmann, J. H. K., D. E. Scott, J. W. Gibbons, and R. D. Semlitsch. 1989. Influence of wetland hydroperiod on diversity and abundance of metamorphosing juvenile amphibians. Wetlands Ecology and Management 1:3-11.

Pechmann, J. H. K., D. E. Scott, R. D. Semlitsch, J. P. Caldwell, L. J. Vitt, and J. W. Gibbons. 1991. Declining am- 
phibian populations: the problem of separating human impacts from natural fluctuations. Science 253:892-895.

Pechmann, J. H. K., and H. M. Wilbur. 1994. Putting amphibian declines in perspective: natural fluctuations and human impacts. Herpetologica 50:65-84.

Roller, N. E. G. 1974. Airphoto mapping of ecosystem development on the Edwin S. George Reserve. Thesis. University of Michigan, Ann Arbor, Michigan, USA.

Sarkar, S. 1996. Ecological theory and anuran declines. Bioscience 46:199-207.

Sjogren-Gulve, P. 1994. Distribution and extinction patterns within a northern metapopulation of the pool frog, Rana lessonae. Ecology 75:1357-1367.

Skelly, D. K. 1992. Larval distributions of spring peepers and chorus frogs: regulating factors and the role of larval behavior. Dissertation. University of Michigan, Ann Arbor, Michigan, USA.

1995. A behavioral tradeoff and its consequences for the distribution of Pseudacris treefrog larvae. Ecology 76:150-164.

. 1996. Pond drying, predators and the distribution of Pseudacris tadpoles. Copeia 1996:599-605. $36-45$.

Skelly, D. K., and E. Meir. 1997. Rule-based models of distributional change. Conservation Biology 11:531-539.

Smith, D. C., and J. Van Buskirk. 1995. Phenotypic design, plasticity, and ecological performance in two tadpole species. American Naturalist 145:211-233.

Wassersug, R. J., and E. A. Seibert. 1975. Behavioral responses of amphibian larvae to variation in dissolved oxygen. Copeia 1975:86-103.
Wellborn, G. A., D. K. Skelly, and E. E. Werner. 1996. Annual Review of Ecology and Systematics 27:337-363.

Werner, E. E. 1991. Nonlethal effects of a predator on competitive interactions between two anuran larvae. Ecology 72:1709-1720.

Werner, E. E., and B. R. Anholt. 1993. Ecological consequences of the tradeoff between growth and mortality rates mediated by foraging activity. American Naturalist 142: 242-272.

Werner, E. E., and K. S. Glennmeier. 1999. Influence of forest canopy on the breeding pond distributions of several amphibian species. Copeia 1999:1-12.

Werner, E. E., and M. McPeek. 1994. Direct and indirect effects of predators on two anuran species along an environmental gradient. Ecology 75:1368-1382.

Wilbur, H. M. 1987. Regulation of structure in complex systems: experimental temporary pond systems. Ecology $\mathbf{6 8}$ : $1437-1452$.

- 1971. Competition, predation, and the structure of the Ambystoma-Rana sylvatica community. Dissertation. University of Michigan, Ann Arbor, Michigan, USA.

- 1972. Competition, predation, and the structure of the Ambystoma-Rana sylvatica community. Ecology 53:321.

2. 1977. Density dependent aspects of growth and metamorphosis in Bufo americanus. Ecology 58:196-200.

Wilbur, H. M., and J. P. Collins. 1973. Ecological aspects of amphibian metamorphosis. Science 182:1305-1314.

Woodward, B. D. 1983. Predator-prey interactions and breeding-pond use of temporary-pond species in a desert anuran community. Ecology 64:1549-1555.

Wright, A. H., and A. A. Wright. 1949. Handbook of frogs and toads of the United States and Canada. Comstock, Ithaca, New York, USA. 